\title{
Cell-Specific Expression from the Human Dopamine $\beta$-Hydroxylase Promoter in Transgenic Mice Is Controlled via a Combination of Positive and Negative Regulatory Elements
}

\author{
Gary W. Hoyle,' Eric H. Mercer, ${ }^{2, a}$ Richard D. Palmiter, ${ }^{2}$ and Ralph L. Brinster ${ }^{1}$ \\ 'Laboratory of Reproductive Physiology, School of Veterinary Medicine, University of Pennsylvania, Philadelphia, \\ Pennsylvania 19104 and ${ }^{2}$ Howard Hughes Medical Institute and Department of Biochemistry, University of Washington, \\ Seattle, Washington 98195
}

\begin{abstract}
The promoter region of the human dopamine $\beta$-hydroxylase (DBH) gene was analyzed in transgenic mice to identify DNA sequences responsible for the tissue- and cell-specific expression of the gene. Transgenic mice were generated that carried the Escherichia coli lacZ gene under control of DBH promoter fragments between 0.6 and 5.8 kilobases $(\mathrm{kb})$ in length. Sequences required for expression in adult and fetal noradrenergic neurons were located between 0.6 and 1.1 kb $5^{\prime}$ to the DBH transcriptional start site. Sequences in this region and farther upstream also directed expression to dopaminergic and noncatecholaminergic brain neurons that was repressed by negative elements elsewhere in the gene. The results indicate that the neuron-specific expression of the DBH gene is mediated by positive regulatory elements but that negative elements are required to restrict expression to the proper subset of neurons.
\end{abstract}

[Key words: dopamine $\beta$-hydroxylase, transgenic mice, gene expression, transcriptional regulation, catecholamines, noradrenergic neurons]

Although many neuron-specific genes have been identified, relatively little is known about the mechanisms by which neuronal transcription is controlled. Knowledge about neuronal gene expression is necessary to understand the normal biology of neurons, their development, and why they die in neurodegenerative disease states. We are pursuing studies investigating the transcriptional control of the genes required for catecholamine biosynthesis (Baetge et al., 1988; Kapur et al., 1991; Mercer et al., 1991). The catecholamines dopamine, norepinephrine, and epinephrine, which are neurotransmitters in the mammalian nervous system, are synthesized from tyrosine via the sequential actions of four enzymes: tyrosine hydroxylase (TH), aromatic amino acid decarboxylasc (AADC), dopaminc $\beta$-hydroxylase $(\mathrm{DBH})$, and phenylethanolamine $N$-methyltransferase (PNMT). TH converts tyrosine to L-dopa, which in turn is acted upon by AADC to generate dopamine. Norepinephrine is produced from

\footnotetext{
Received June 24, 1993; revised Sept. 22, 1993; accepted Oct. 26, 1993.

We thank Mary Avarbock, Glenda Froelick, Diane Allen, and Felicity Oram for excellent technical assistance. This work was supported by NIH Grants HD 23657 (R.L.B.) and HD 09172 (R.D.P.).

Correspondence should be addressed to Gary W. Hoyle, Laboratory of Reproductive Physiology, School of Veterinary Medicine, University of Pennsylvania, 3850 Baltimore Avenue, Philadelphia, PA 19104

a Present address: Division of Biology, 21676, California Institute of Technology, Pasadena, CA 91125.

Copyright (C) 1994 Society for Neuroscience $0270-6474 / 94 / 142455-09 \$ 05.00 / 0$
}

dopamine by DBH, and finally, norepinephrine is methylated by PNMT to yield epinephrine. The combination of enzymes present in a given neuron determines the catecholamine neurotransmitter produced. Thus, dopaminergic neurons contain TH and AADC, noradrenergic neurons contain TH, AADC, and $\mathrm{DBH}$, and adrenergic neurons contain all four catecholamine biosynthetic enzymes. The catecholamine biosynthetic genes constitute a good system for studying neuronal transcription since they are expressed specifically in neurons and neuroendocrine cells, and since the cxpression patterns of the genes in central and peripheral neurons have been documented by immunohistochemical and catecholamine histofluorescence methods. In addition, the expression patterns of the individual genes partially overlap, yet each gene has a unique pattern of expression. As a result, an investigation of the DNA sequences associated with these genes will potentially reveal enhancer elements common to the pathway as a whole, as well as elements required to generate the unique expression of the individual genes.

As a first step toward investigating the transcriptional regulation of one of the catecholamine genes, we previously generated transgenic mice in which reporter genes were expressed from the promoter region of the human DBH gene (Kapur et al., 1991; Mercer et al., 1991). In adult mice carrying $5.8 \mathrm{ki}-$ lobases $(\mathrm{kb})$ of the DBH promoter region fused to the Escherichia coli lac $Z$ structural gene, $\beta$-galactosidase expression was detected in cell types that had previously been documented to express DBH, including adrenal chromaffin cells (Fuxe et al., 1971), sympathetic neurons (Fuxe et al., 1971), noradrenergic neurons in the brain (Swanson and Hartman, 1975), and some enteric (Baetge et al., 1990) and parasympathetic neurons (Grzanna and Coyle, 1978; Landis et al., 1987). Some $\beta$-galactosidase expression was also obscrved in unexpected sites, including dorsal root ganglia and dopaminergic and noncatecholaminergic nuclei in the brain. In fetal mice, proper developmental expression of the DBH-lacZ transgene was observed in noradrenergic neurons, as was unexpected transient expression in sensory ganglia, ventral spinal cord, and facial mesenchyme (Kapur et al., 1991). The expression pattern in DBH-lacZ mice indicated that the elements required for expression of DBH in noradrenergic neurons and adrenal chromaffin cells are contained within the $5.8 \mathrm{~kb}$ of DNA $5^{\prime}$ to the DBH structural gene, but that this DNA fragment did not fully reproduce the expression pattern expected for $\mathrm{DBH}$, since expression was observed in sites where $\mathrm{DBH}$ has not been detected. 


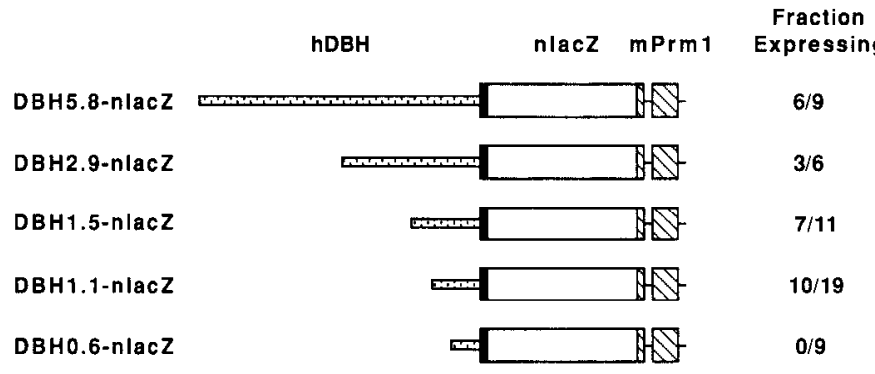

Figure 1. DBH-nlacZ DNA constructs. The DNA constructs used to generate transgenic mice contained a fragment of variable length from the 5 ' region of the human $\mathrm{DBH}$ gene (stippled. $h D B H$ ), the $E$. coli lac $Z$ structural gene (open box) that had been modified by the addition of a nuclear localization signal from SV40 large T-antigen (black, nlacZ; Mercer et al., 1991), and an intron and eukaryotic polyadenylation signal from the $3^{\prime}$ region of the mouse protamine 1 gene (hatched, $m$ Prml). Numbers at the right indicate the fraction of transgenic mouse lines or founders that expressed the transgene (number expressing/total number examined).

Here we report an initial dissection of the human DBH $5^{\prime}$ region to map the location of DNA sequences necessary for the transcriptional regulation of the DBH gene. Transgenic mice were generated in which transcription of the $E$. coli lac $Z$ gene was driven by different lengths of DBH $5^{\prime}$ sequences, and the expression of the reporter gene in adult mice and during development was determined. Our results show that the pattern of DBH expression results from the combined effect of positive transcriptional elements producing expression in noradrenergic neurons plus some dopaminergic and noncatecholaminergic neurons, in conjunction with negative elements that repress expression in the neurons that do not produce $\mathrm{DBH}$.

\section{Materials and Methods}

The DBH5.8-nlac $Z$ construct is the same as described previously (Mercer et al., 1991). The DBH2.9-nlac $Z$ and DBH0.6-nlac $Z$ constructs were generated by cutting the previously described pDBH-nlac $Z$ plasmid with SstII and SphI or KpnI and SphI, respectively. The DBH1.5-nlacZ and $\mathrm{DBH} 1.1-\mathrm{n} l a c Z$ constructs were obtained from a Bal 31 deletion series that started at the SstII site at $2.9 \mathrm{~kb} 5^{\prime}$ to the DBH transcription start site. The $5^{\prime}$ end-points for the DBH1.5-nlacZ and DBH1.1-nlac Z genes are 1510 and 1065 base pairs (bp) upstream of the DBH transcriptional start site, respectively. Transgenic mice were generated by injection of linearized DNA constructs into fertilized mouse eggs and identified by dot hybridization of tail DNA with transgene-specific probes as described (Brinster et al., 1985).

5 -Bromo-4-chloro-3-indoyl $\beta$-D-galactopyranoside (X-gal) staining of mouse tissues and fetuses was performed as described (Mercer et al., 1991). Tyrosine hydroxylase was detected in tissue sections using a sheep anti-TH antiserum (Pel-Freeze, Rogers, AR). For colocalization of X-gal staining and TH immunoreactivity, thick (approximately $5 \mathrm{~mm}$ ) slices of brain were stained with X-gal, fixed in 10\% formalin, cryoprotected in $20 \%$ sucrose, frozen, and sectioned at $15 \mu \mathrm{m}$ using a cryostat. Sections were thaw mounted onto gelatin-coated slides and stained with anti$\mathrm{TH}$ antibodies diluted 1:200. Bound antibodies were detected by the ABC method (Vectastain Elite, Vector Laboratories, Burlingame, CA) according to instructions from the supplier. DBH immunohistochemistry was performed using a rabbit anti-DBH antiserum (Eugene Tech International, Ridgefield Park, NJ) diluted 1:2000, and bound antibodies were detected by the ABC method (Vectastain Elite, Vector Laboratories, Burlingame, $\mathrm{CA}$ ).

\section{Results}

We demonstrated previously that $5.8 \mathrm{~kb}$ of DNA $5^{\prime}$ to the transcriptional start site in the human DBH gene directed expression of the $E$. coli lac $Z$ gene to cells in which DBH is known to be expressed (Mercer et al., 1991). Therefore, the $5.8 \mathrm{~kb}$ DBH gene
Table 1. Expression of DBH-nlac $Z$ constructs in adult mice

Length of DBH $5^{\prime}$ sequence $(\mathrm{kb})$

\begin{tabular}{llllll}
\cline { 2 - 5 } Tissue & 5.8 & 2.9 & 1.5 & 1.1 & 0.6 \\
\hline Adrenal & + & + & + & + & - \\
Sympathetic ganglia & + & + & + & + & - \\
Enteric ganglia & + & $\mathrm{ND}$ & + & + & - \\
Brainstem noradrenergic nuclei $_{\text {Cranial sensory ganglia }}{ }^{a}$ & + & + & + & + & - \\
Cranial parasympathetic ganglia $^{b}$ & + & $\mathrm{ND}$ & + & + & - \\
Substantia nigra & + & $\mathrm{ND}$ & + & + & - \\
Preoptic area $_{\text {Hypothalamus }}$ & + & - & - & - & - \\
Septum & + & - & - & - & - \\
Olfactory bulb & $+c$ & $+c$ & - & $+^{c}$ & - \\
& - & - & - & + & - \\
Dlf & - & - & - & + & -
\end{tabular}

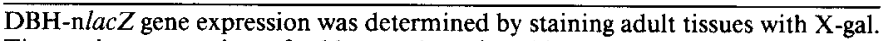
Tissues in top portion of table are those in which DBH expression has been documented. Tissues in bottom portion of table are those in which $\beta$-galactosidase expression was detected but DBH expression has not been reported. Substantia nigra, preoptic area, and hypothalamus are included as examples of ectopic brain expression in DBH5.8-nlacZ mice, but expression was observed in a number of other unexpected brain areas (see Mercer et al., 1991, for details). ND, not determined.

a The sensory ganglia examined were the trigeminal and vagal ganglia.

"The parasympathetic ganglia examined were the submandibular, otic, sphenopalatine, and ciliary ganglia.

"Sites of hypothalamic expression in DBH5.8-nlacZ differed from those in DBH 1.1$\mathrm{n} l a c Z$ mice, as described in Results. The DBH2.9-nlac $Z$ founder mice that were examined appeared to be mosaic, since very few expressing hypothalamic cells were detected. It was therefore difficult to determine whether the hypothalamic pattern was similar to that observed in other $\mathrm{DBH}-\mathrm{n} l a c \mathrm{Z}$ mice.

fragment contains the information required for expression in DBH-producing cells. To localize the required elements further, we generated transgenic mice carrying shorter promoter fragments fused to the lac $Z$ gene. The series of fusion genes used in this study is shown in Figure 1 , and consists of promoter fragments $5.8 \mathrm{~kb}, 2.9 \mathrm{~kb}, 1.5 \mathrm{~kb}, 1.1 \mathrm{~kb}$, and $0.6 \mathrm{~kb}$ in length fused to a $l a c Z$ reporter gene. The lac $Z$ gene ( $l a c Z$ ) has been modified by the addition of a nuclear targeting signal from SV40 T-antigen (Mercer et al., 1991). In expressing cells, the nlacZ gene allows identification of the soma without the potential interference from gene product in neuronal processes.

Transgenic mice carrying the DBH-nlac $Z$ fusion genes in Figure 1 were generated by pronuclear microinjection of DNA into fertilized mouse eggs (Brinster et al., 1985), and the expression of the lac $Z$ gene was examined by histochemical staining with the chromogenic substrate $X$-gal. Transgenic mice derived from between 6 and 19 transgenic founder mice were examined for each construct, and the fraction in which transgene expression was observed is indicated in Figure 1. For most constructs, a smaller number of transgenic mouse lines (usually two or three) in which $\beta$-galactosidase expression was observed was established and examined in greater detail. For the DBH2.9-nlacZ construct, none of the expressing founder mice passed the transgene to progeny (probably because they were mosaic for the transgene), so the expression pattern for this construct was compiled from founder mice. For the remaining DNA constructs, the expression patterns reported below were consistently observed in multiple transgenic lines.

The tissue distribution of DBH-nlacZ fusion gene expression was examined in adult mice (Table 1). Expression of the lac $Z$ reporter gene in normal sites of $\mathrm{DBH}$ production cosegregated 

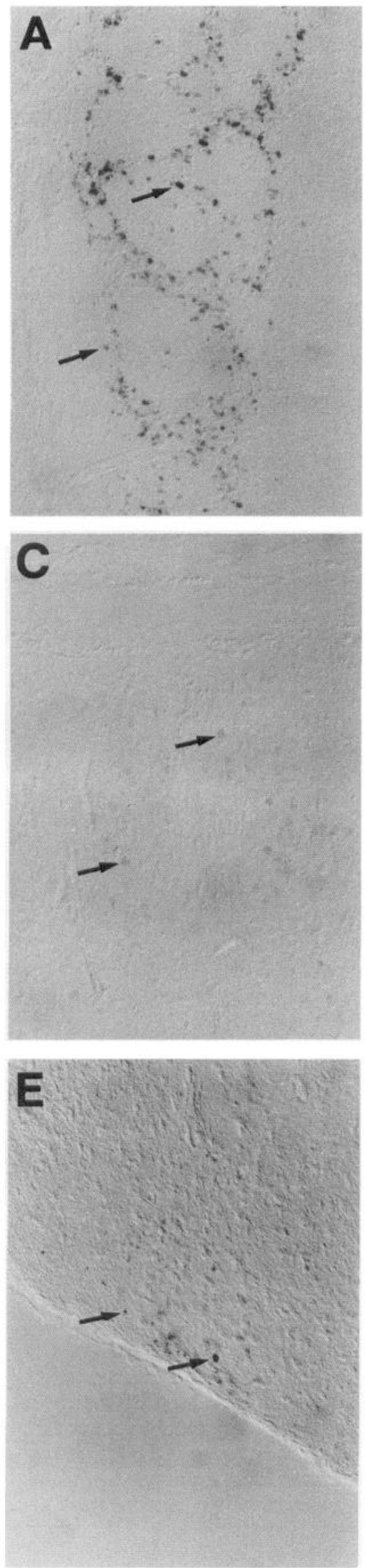

B

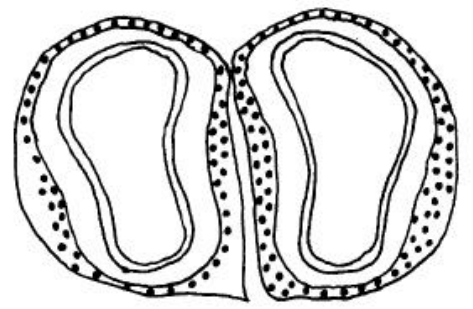

D

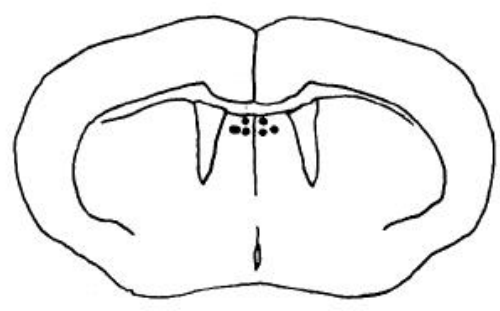

$\mathbf{F}$

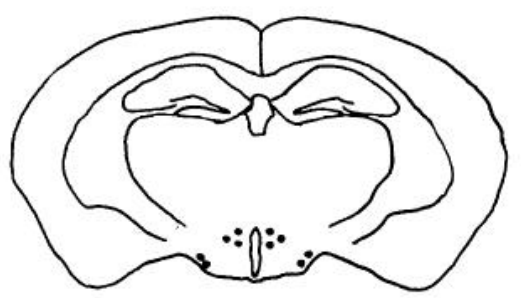

Figure 2. Brain expression of DBH1.1 nlac $Z$ gene. $A, C$, and $E$ are photographs showing $\beta$-galactosidase-expressing cells (examples indicated by arrows) in olfactory bulb $(A)$, septum $(C)$, and ventrolateral hypothalamus (E). Slices of brain approximately $5 \mathrm{~mm}$ thick were stained with $\mathrm{X}$-gal, fixed overnight in $10 \%$ formalin, cryoprotected with $20 \%$ sucrose, sectioned at $15 \mu \mathrm{m}(A)$ or $50 \mu \mathrm{m}(C$ and $E)$ with a cryostat, thaw mounted onto gelatincoated slides, and photographed using Nomarski optics. $B, D$, and $F$ are brain drawings at levels corresponding to the adjacent photographs. Areas that contained $\beta$-galactosidase-expressing cells are indicated by solid circles. 
Tahle 2. Fxpression of DBH-nlac $Z$ constructs in F10.5 mice

\begin{tabular}{lccccc} 
& \multicolumn{6}{c}{ Length of DBH $5^{\prime}$ sequence $(\mathrm{kb})$} \\
\cline { 2 - 6 } Tissue & 5.8 & 2.9 & 1.5 & 1.1 & 0.6 \\
\hline Sympathetic chain & + & ND & + & + & - \\
Brain & + & ND & + & + & - \\
Cranial sensory ganglia & + & ND & + & + & - \\
Enteric ganglia & + & ND & + & + & - \\
Spinal cord & + & ND & - & - & - \\
Dorsal root ganglia & + & ND & - & - & - \\
Facial mesenchyme & + & ND & - & - & -
\end{tabular}

DBH-nlacZ gene expression was determined by staining E10.5 fetuses with X-gal. Tissues in top portion of table are those in which expression was detected from E9.5 onward to adulthood in DBH5.8-nlacZ mice. Tissues in bottom portion of table are those in which transient expression from E9.5 to E14.5 was observed in DBH5.8-nlacZ mice. ND, not determined.

in all of the DBH-nlacZ transgenic mice we examined; either expression was seen in all the sites or it was not seen in any. Fusion genes containing $5.8,2.9,1.5$, or $1.1 \mathrm{~kb}$ of $\mathrm{DBH} 5^{\prime}$ sequence resulted in X-gal staining in adrenal medulla, noradrenergic brainstem nuclei, and sympathetic, enteric, and cranial parasympathetic and sensory ganglia (except the $\mathrm{DBH} 2.9-\mathrm{n} l a c Z$ construct, for which expression in enteric and cranial ganglia was not examined). Staining in these sites was similar to that previously reported for the DBH5.8-nlacZ construct (Mercer et al., 1991). As was found for the DBH5.8-nlacZ gene, all the transgenic lines carrying the shorter DNA constructs exhibited incomplete penetrance of reporter gene expression. The fraction of transgene-expressing neurons in the superior cervical ganglion varied among different animals within a transgenic line, ranging from $<10 \%$ to $>90 \%$. There did not appear to be any consistent differences among the different DNA constructs regarding the expression penetrance. However, the staining intensity per cell in the DBH1.5-nlacZ and DBH1.1-nlac Z transgenic mouse lines was generally weaker than that observed in lines carrying the two constructs with the longer promoter fragments. For these four constructs, staining in adult mice was observed only in neurons and adrenal chromaffin cells. The shortest fusion gene, containing $0.6 \mathrm{~kb}$ of DBH 5' sequence, showed no expression at any site. These results indicate the presence of a transcriptional regulatory element between $-0.6 \mathrm{~kb}$ and $-1.1 \mathrm{~kb}$ in the human $\mathrm{DBH} 5^{\prime}$ region that is required for expression in $\mathrm{DBH}-$ producing cells.

The brain expression patterns in DBH-nlacZ transgenic mice were characterized by expression in neurons that synthesize DBH and in other neurons, and by significant changes in expression as the length of the DBH $5^{\prime}$ sequence was varied (Table 1). In mice carrying the DBH5.8-nlacZ gene, expression was observed in noradrenergic brainstem nuclei as well as in unexpected brain areas, including regions of the tegmentum, preoptic area, hypothalamus, and cerebral cortex (Mercer et al., 1991). Brain expression of the $\mathrm{nlacZ}$ gene in $\mathrm{DBH} 2.9-\mathrm{n}$ lac $\mathrm{Z}$ mice was seen in brainstem noradrenergic neurons, but the expression in other areas was more restricted than that seen in DBH5.8-nlacZ mice. However, this obscrvation is difficult to interpret, since expression was examined only in founder mice that appeared to be mosaic for the transgene. Weak staining in the hypothalamus was observed, suggesting that, like the DBH5.8-nlacZ construct, the DBH2.9-nlac $Z$ construct results in ectopic brain expression. Expression in DBH1.5-nlacZ mice differed significantly from that in DBH5.8-nlacZ mice in that it was only detected in noradrenergic nuclei, including A1, A2, A4/A6 (locus coeruleus), $A 5$, and $A 7$, but not in other areas of the brain. Therefore, brain expression of the $\mathrm{n} / a c Z$ gene in $\mathrm{DBH} 1.5-\mathrm{n}$ lac $Z$ mice appears to mimic expression of the endogenous DBH gene. Further deletion of the DBH $5^{\prime}$ sequence to $1.1 \mathrm{~kb}$ resulted in novel expression in three additional sites: olfactory bulb, septum, and hypothalamus. Expression in the olfactory bulb was confined to the periglomerular region of the glomerular layer (Fig. $2 A, B$ ). Brain expression in the septum was observed in the extreme dorsal region in cells near the midline (Fig. 2C,D), expanding caudally in a thin band laterally and slightly ventrally. In the hypothalamus of DBH1.1-nlac Z mice, X-gal staining was seen in a group of cells ventral and lateral to the ventral premammillary nucleus and in scattered cells in and around the ventromedial hypothalamic nucleus (Fig. $2 E, F$ ). Mice carrying the DBH5.8-nlacZ gene, in which transgene expression was obscrved in many non-noradrencrgic sites, did not exhibit expression in the olfactory bulb or septum. In the hypothalamus of DBH5.8-nlacZ mice, transgene expression was more widespread, being expressed in suprachiasmatic, periventricular, medial zona incerta, arcuate, and dorsomedial nuclei, but was absent from the ventromedial nucleus (Mercer et al., 1991). This pattern was clearly distinct from that observed in DBH1.1$\mathrm{n}$ lac $Z$ mice, suggesting that distinct DNA regulatory elements mediate hypothalamic expression in the two different transgenic lines. The olfactory bulb, septum, and hypothalamus were examined for endogenous DBH expression by immunohistochemistry, but no DBH immunoreactivity was detected. The brain expression patterns generated by the DBH promoter fusion genes indicate the presence of a positive regulatory element between $-5.8 \mathrm{~kb}$ and $-1.5 \mathrm{~kb}$ relative to the $5^{\prime}$ end of the DBH coding sequence that directs expression to non-noradrenergic brain neurons, and a negative element between $-1.5 \mathrm{~kb}$ and $-1.1 \mathrm{~kb}$ that prevents expression in the three novel sites observed in DBH1.1-nlacZ brains.

Since the expression of DBH and TH overlaps in many cells, common enhancer elements may contribute to the tissue- and cell-specific expression of the two genes. We previously detected expression of the DBH5.8-nlacZ gene in many brain areas not

\footnotetext{
Figure 3. (top) Coexpression of TH and $\beta$-galactosidase in the olfactory bulb of DBH1.1-nlacZ mice. $A$, Transverse section through the olfactory bulb of DBH 1.1-nlac $Z$ mouse stained for $\beta$-galactosidase activity and TH immunoreactivity. Some neurons express both $\beta$-galactosidase and TH (large arrows), while some express only $\beta$-galactosidase (arrowheads) or TH (small arrows). $B$, Adjacent section showing staining when the primary antiserum was omitted. Scale bars, $20 \mu \mathrm{m}$.

Figure 4. (hottom) Fetal expression of DBH1.1-nlac7 gene. A, Whole-mount F10.5 fetus carrying the DBH1.1-nlacZ gene. X-gal staining is observed in the sympathetic chain, brain, and cranial nerve ganglia. Staining is absent from the spinal cord, dorsal root ganglia, and facial mesenchyme. $s g$, sympathetic ganglia; $v$, ganglion of vagus nerve; $f$, ganglion of facial nerve; $b s$, brainstem. $B$, Paraffin section $(6 \mu \mathrm{m})$ through thoracic region of E10.5 DBH1.1-nlacZ fetus showing X-gal staining in sympathetic ganglia (arrows) and its absence from the spinal cord (sc) and dorsal root ganglia (d). Similar results were obtained for DBH1.5-nlacZ fetuses. Scale bars: $A, 0.5 \mathrm{~mm} ; B, 50 \mu \mathrm{m}$.
} 


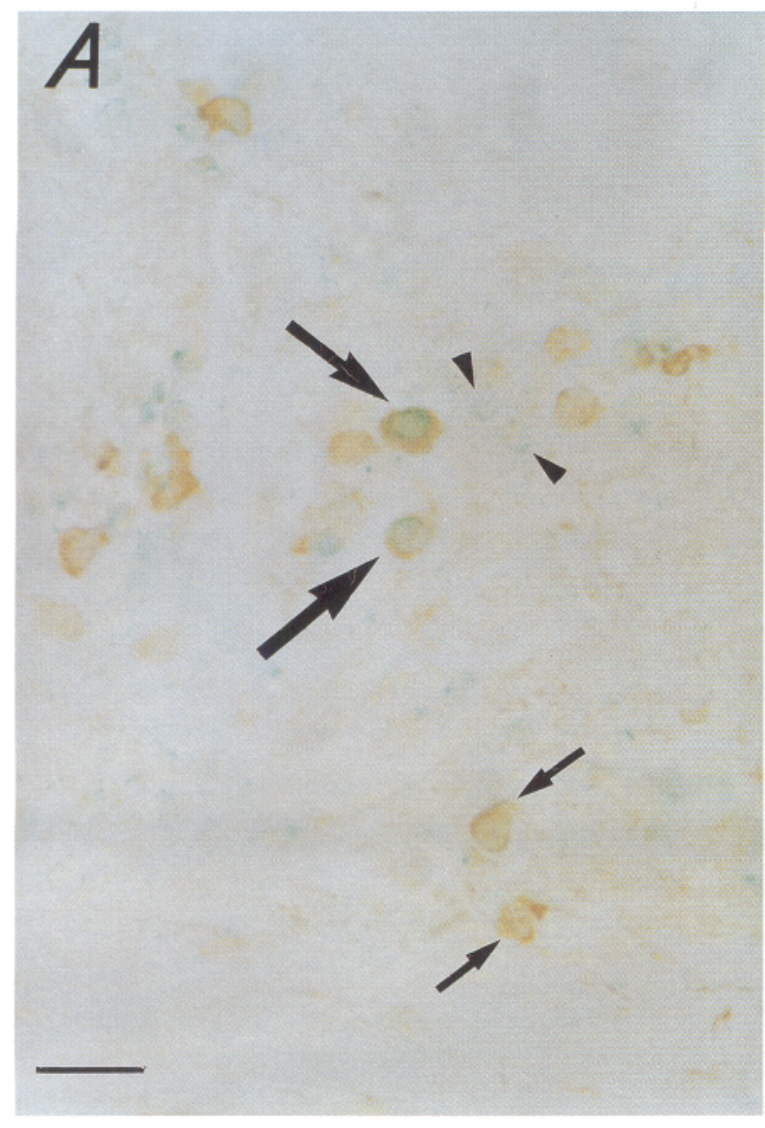

B
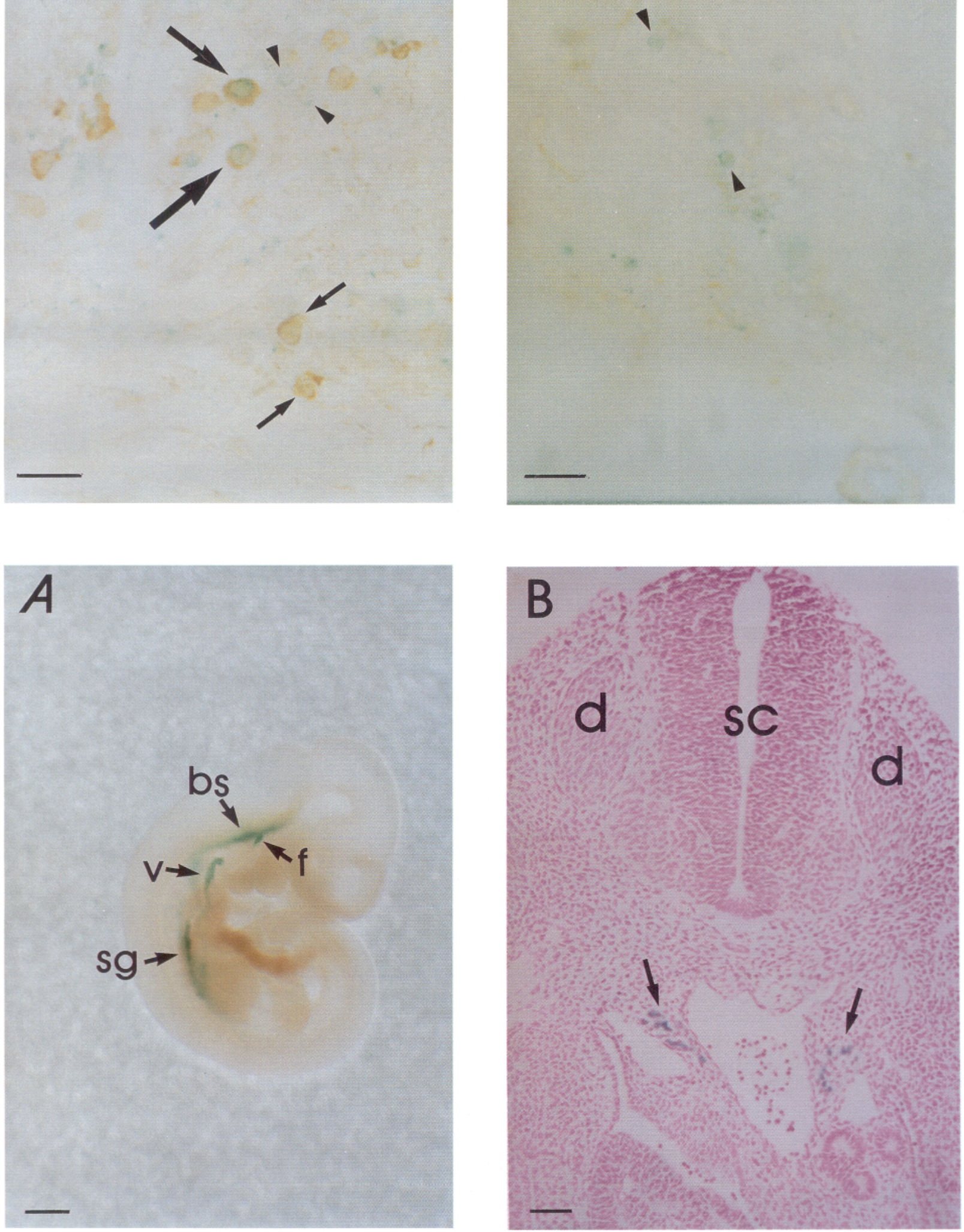


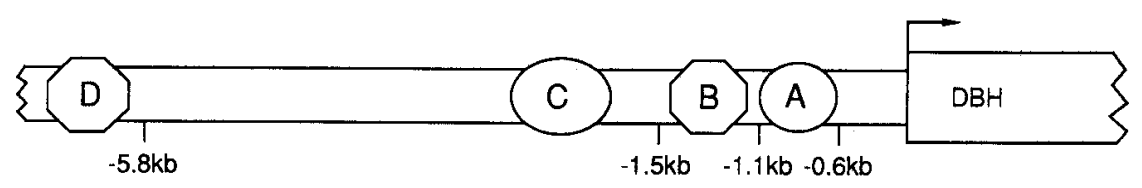

\begin{tabular}{lc}
\multicolumn{1}{c}{ Cell Type } & Sites lnvolved \\
NE neurons / chromaffin cells & $A(+C ?)$ \\
Neurons in olfactory bulb / septum / hypothalamus & $A+B$ \\
Multiple non-NE CNS neurons & $C+D$
\end{tabular}

Figure 5. Model for location of transcriptional regulatory elements in 5 ' region of the human DBH gene. At the top is a schematic drawing of the 5 ' region of the DBH gene with the location of regulatory elements (labeled $A-D$ ) identified in this study. These elements act in conjunction with proximal promoter elements (not shown in drawing) to bring about the proper tissue- and cell-specific expression of the DBH gene. $A$ is a positive element between $-0.6 \mathrm{~kb}$ and $-1.1 \mathrm{~kb}$ that brings about gene expression in noradrenergic neurons and some non-noradrenergic brain neurons. $C$ is a positive element between $-1.5 \mathrm{~kb}$ and $-5.8 \mathrm{~kb}$ that results in expression in additional dopaminergic and noncatecholaminergic brain neurons. $B$ is a negative regulatory element between $-1.1 \mathrm{~kb}$ and $-1.5 \mathrm{~kb}$ that leads to inhibition of expression in neurons of the olfactory bulb, septum, and hypothalamus. $D$ is a negative element outside the region we examined that represses the ectopic brain expression produced by element $C$. At the bottom is a list of cell types and their proposed ability to produce transcription factors that bind specifically to the individual sites. See Discussion for details.

known to contain DBH-producing cells, but which did contain TH-producing cells. Colocalization of $\beta$-galactosidase activity and TH immunoreactivity showed that some, but not all, $\beta$-galactosidase-expressing cells in these brain areas also expressed TH (Mercer et al., 1991). Since one of the novel sites of expression in DBH1.1-nlacZ mice, the olfactory bulb, contains dopaminergic neurons (Halász et al., 1977), it was of interest to determine whether cells expressing the transgene also express TH. Sections through the olfactory bulb of DBH1.1-nlac Z mice were stained for both $\beta$-galactosidase activity and TH immunoreactivity (Fig. 3). TH staining was observed in cell bodies of periglomerular neurons and in fibers within the glomeruli. Cells were observed that exhibited both nuclear X-gal staining and cytoplasmic TH staining, and others were observed that contained only X-gal or TH staining. These results are similar to those obtained in dopaminergic brain regions of DBH5.8$\mathrm{n} l a c Z$ mice, such as the substantia nigra, in which $\mathrm{X}$-gal staining was detected in neurons that contained $\mathrm{TH}$, but an exact correlation between transgene and $\mathrm{TH}$ expression was not observed. In the septum and hypothalamus, the other two sites of $\beta$-galactosidase expression in DBH1.1-nlac $Z$ brains, no colocalization of TH immunoreactivity and X-gal staining was observed, which indicated that in these sites, $\beta$-galactosidase was expressed in noncatecholaminergic neurons.

We examined DBH-nlacZ fetuses to identify the DBH promoter sequences that arc rcquircd for proper developmental expression of the DBH gene. We previously described the pattern of $\beta$-galactosidase expression in fetuses that carried the DBH5.8-nlac $Z$ gene (Kapur et al., 1991). At embryonic day 10.5 (E10.5), expression was detected in the sympathetic chain, brain, ventral spinal cord, cranial sensory ganglia, dorsal root ganglia, gut, and a region of facial mesenchyme. Expression in the sympathetic chain, brain, and enteric nervous system was observed at all later stages of development and continued into the adult, while expression in cranial sensory ganglia, dorsal root ganglia, and facial mesenchyme was transient and became localized to a smaller number of cells or disappeared entirely in later stages of development. Expression of $\beta$-galactosidase in
DBH1.5-nlac' $2, \mathrm{DBH} 1.1-\mathrm{n} /$ acZ, and DBH0.6-nlacZ fetuses was compared to that in DBH5.8-nlac $Z$ fetuses to determine the location of promoter sequences required for fetal expression of the DBH gene. The DBH1.5-nlac $Z$ and DBH1.1-nlacZ genes had similar expression patterns that were more restricted than the DBH5.8-nlacZ pattern (Table 2). At E10.5, DBH1.5-nlacZ and DBH1.1-nlacZ fetuses exhibited X-gal staining in the sympathetic chain, brain, enteric nervous system, and some cranial sensory ganglia (trigeminal, facial, glossopharyngeal, and vagal nerve ganglia), but not dorsal root ganglia, spinal cord, or facial mesenchyme (Fig. 4). Staining was also seen in these same sites in E14.5 fetuses carrying the DBH1.5-nlacZ and DBH1.1-nlacZ genes (not shown), as was staining in the developing adrenal gland, as described previously for DBH5.8-nlacZ fetuses (Kapur et al., 1991). No fetal expression was detected in mice carrying the $\mathrm{DBH} 0.6-\mathrm{n} l a c Z$ gene. These results indicate that sequences required for fetal expression in noradrenergic neurons are contained within the $1.1 \mathrm{~kb}$ promoter fragment and that sequences responsible for the transient expression in other neurons lie between -1.5 and $-5.8 \mathrm{~kb}$ relative to the transcriptional start site in the human DBH gene.

\section{Discussion}

The results of this study show that the $5^{\prime}$ region of the DBH gene contains multiple sequence elements involved in both positive and negative control of DBH gene expression. The DBH1.1$\mathrm{n} l a c Z$ gene directed $\beta$-galactosidase expression to adrenal chromaffin cells, central and peripheral noradrenergic neurons, and other neurons in which DBH has been detected, such as cranial parasympathetic and enteric neurons. This length of DBH promoter sequence was also sufficient to direct fetal expression of $\beta$-galactosidase to noradrenergic neurons. The lack of embryonic or adult expression observed in mice carrying the DBH0.6$\mathrm{n} l a c Z$ gene indicated that sequence elements essential for expression in noradrenergic neurons were present between -0.6 $\mathrm{kb}$ and $-1.1 \mathrm{~kb}$ relative to the human DBH transcriptional start site. This does not rule out the presence of additional essential elements within the $0.6 \mathrm{~kb}$ fragment, but these cannot be de- 
tected by the present analysis. In addition to expression in noradrenergic neurons, the $1.1 \mathrm{~kb} \mathrm{DBH}$ promoter fragment brought about $\beta$-galactosidase expression in neurons of the olfactory bulb, septum, and hypothalamus, in which $\mathrm{DBH}$ could not be detected. In mice carrying the DBH1.5-nlacZ gene, expression in the three areas was repressed, indicating the presence of a negative regulatory element between -1.1 and $-1.5 \mathrm{~kb}$. A second positive regulatory element was identified between -1.5 and $-5.8 \mathrm{~kb}$ that brought about widespread brain expression, including tegmental, hypothalamic, and cortical areas. This expression is presumably repressed by a second negative element, either farther $5^{\prime}$ of the gene, or within or $3^{\prime}$ to the gene. Finally, the region between -1.5 and $-5.8 \mathrm{~kb}$ contained an element responsible for the transient expression we observed in sensory neurons, spinal cord, and facial mesenchyme.

A model for the transcriptional regulation of the human $\mathrm{DBH}$ gene incorporating the existence of the elements we identified is shown in Figure 5. The model assumes that transcription of the DBH gene is controlled via proximal promoter sequences in combination with more distal regulatory elements. We identified at least four regions containing distinct elements, designated A-D. The simplest model consistent with the data is shown; each of the four regions potentially could contain multiple elements responsible for expression in smaller subgroups of cells. $A$ and $C$ are positive regulatory elements responsible for expression in multiple regions, while $B$ and $D$ are negative elements that can restrict expression to a subset of regions specified by the positive elements when present in combination. Element $A$ (located between $-0.6 \mathrm{~kb}$ and $-1.1 \mathrm{~kb}$ ) directs expression to noradrenergic neurons, adrenal chromaffin cells, enteric neurons, and some neurons in the olfactory bulb, septum, and hypothalamus. When present, element $B$ (between $-1.1 \mathrm{~kb}$ and $-1.5 \mathrm{~kb})$ is able to repress expression in the latter three sites, giving the pattern observed for the $\mathrm{DBH} 1.5-\mathrm{nlacZ}$ construct. When element B is deleted, as in the DBH1.1-nlacZ construct, the full pattern generated by element $\mathrm{A}$ is manifested. Element $C$ directs expression to dopaminergic sites outside the olfactory bulb and to other brain neurons, but its activity in the endogenous $\mathrm{DBH}$ gene is normally blocked by the presence of negative element $\mathrm{D}$. Element $\mathrm{C}$ may also be responsible for transient embryonic expression in neurons of the ventral spinal cord and sensory ganglia. This model makes specific predictions about the transcription factors expressed by the various subtypes of catecholaminergic neurons. For instance, the transcription factor binding to element B must be expressed in olfactory bulb dopaminergic neurons, but in order to get $\mathrm{DBH}$ expression in noradrenergic neurons, these cells must lack transcription factor $B$ activity. Similar reasoning applies to the non-noradrenergic brain neurons in which $\beta$-galactosidase expression is observed in DBH5.8-nlacZ mice. In these cells, a factor binding to element $\mathrm{C}$ is involved in transcriptional activation but its activity is normally repressed via element $\mathrm{D}$, so DBH is not expressed. Binding to element $\mathrm{C}$ is not required for the tissue specificity of expression in noradrenergic neurons, but may contribute to the level of expression, as discussed below.

We detected two regions of the DBH promoter that directed expression to neurons that normally do not produce DBH (elements $A$ and $C$ in Fig. 5). It is not obvious why elements that direct expression to these sites should be present in the DBH gene, since their activity appears to be repressed by negative regulatory elements elsewhere. One possible explanation is that many enhancer elements involved in neuron-specific transcrip- tion may have multiple functions whereby they control expression in different cell types. For example, element A directs expression to multiple cell types, only some of which produce $\mathrm{DBH}$. The $\mathrm{DBH}$ gene has additional regulatory elements to suppress expression in cells that do not produce DBH. Perhaps other genes, such as those cxpressed in the olfactory bulb, have different negative elements that, in conjunction with the same positive regulatory element, generate a different or overlapping expression pattern. This arrangement may be necessary to produce the exceedingly complex pattern of gene expression in the mammalian nervous system without the need for an inordinately large number of transcription factors. When one gene is examined in isolation, it appears that more factors than necessary are involved, but a network of factors with multiple functions may be the most efficient arrangement for the system as a whole. A second possibility to explain the apparent redundancy of transcriptional elements is that some elements serve to regulate the level of expression in addition to influencing the cell and tissue specificity. For example, element $\mathrm{C}$ is not required to direct expression to noradrenergic neurons, since both DBH1.5-nlac $Z$ and DBH1.1-nlac $Z$ mice exhibit expression in noradrenergic neurons. However, this element may serve to increase the level of expression in noradrenergic neurons, with the by-product of its presence being expression in other cell types, which is repressed by a negative element. Consistent with this hypothesis, we observed that the level of expression, as determined by the intensity of X-gal staining, was generally lower in DBH1.5-nlacZ and DBH1.1-nlacZ mice than in DBH5.8-nlacZ and 2.9-nlacZ mice.

Our results in transgenic mice differed from results in which the regulation of gene expression by the DBH 5' region was examined in cultured cells. DNA fragments containing less than $300 \mathrm{bp}$ of the rat (Shaskus et al., 1992) and human (Lamouroux et al., 1993) DBH genes were sufficient to drive reporter gene expression in catecholaminergic cell lines, but not in non-neuronal cells. These results indicated that some elements involved in the tissue-specific expression of the $\mathrm{DBH}$ gene are present very close to the $\mathrm{DBH}$ proximal promoter region. In contrast, our present results indicate that necessary regulatory elements lay many kilobases $5^{\prime}$ to the start of the DBH gene. The distinction between these results suggests that the requirements for tissue-specific expression are more stringent in transgenic mice than in cultured cells. The DBH gene is likely to contain both proximal and distal transcriptional regulatory elements, of which only the proximal elements are required for expression in cultured cells, but both proximal and distal elements are required for expression in transgenic mice. This type of phenomenon has been observed with other genes as well (Pinkert et al., 1987; Graves et al., 1991).

Ectopic expression from the human DBH promoter in transgenic mice has been reported by others (Kobayashi et al., 1992 Morita et al., 1993). A $4 \mathrm{~kb}$ fragment from the 5 ' region of the human DBH gene directed expression of the PNMT structural gene to noradrenergic neurons, as well as to some dopaminergic and noncatecholaminergic neurons. These results differed from our results with the $5.8 \mathrm{~kb}$ DBH promoter fragment in that the sites of ectopic expression do not completely overlap. For example, expression of the PNMT gene from the $4 \mathrm{~kb} \mathrm{DBH}$ promoter was detected in the cerebellum, hippocampus, and olfactory bulb. We never observed cerebellar or hippocampal expression with any of the DBH-nlac $Z$ constructs and observed olfactory bulb expression only in $\mathrm{DBH} 1.1-\mathrm{n} l a c Z$ mice. The dif- 
ferences in the sites of expression may result from the reporter gene used to detect expression. The bacterial lac $Z$ gene we used is predicted to be inert with regard to its effects on eukaryotic transcription. The PNMT gene, on the other hand, is a member of the catecholamine biosynthetic gene family and may contain sequences that interact with DBH promoter elements to modify its expression. An alternative explanation is that the $4 \mathrm{~kb} \mathrm{DBH}$ promoter fragment contains regulatory elements between 2.9 $\mathrm{kb}$ and $4 \mathrm{~kb}$ that direct expression to the ectopic sites observed by Kobayashi et al. (1992), but in mice carrying the DBH5.8$\mathrm{n} l a c Z$ gene, this expression is repressed by negative elements between $4 \mathrm{~kb}$ and $5.8 \mathrm{~kb}$.

We previously detected expression in DBH5.8-nlac $Z$ mice in many brain areas that contain dopaminergic neurons, which produce $\mathrm{TH}$ but not $\mathrm{DBH}$. One of the few dopaminergic sites in which the DBH5.8-nlacZ gene was not expressed was the glomerular layer of the olfactory bulb. It was therefore intriguing that we observed expression of the DBH1.1-nlacZ gene in periglomerular olfactory bulb neurons and that $\beta$-galactosidase and $\mathrm{TH}$ expression colocalized in some of these neurons. The expression patterns of TH and DBH overlap in many cells and therefore the genes may share common regulatory elements. Our results support the existence of DNA regulatory elements in the $\mathrm{DBH}$ gene that are recognized in dopaminergic neurons, since expression of DBH-nlac $Z$ constructs was observed in most dopaminergic brain nuclei. These observations are consistent with a model in which the TH and DBH genes share common positive regulatory elements that direct expression to dopaminergic, noradrenergic, and other neurons, but have unique combinations of negative elements to restrict expression to dopaminergic and noradrenergic neurons, respectively. Experimental evidence for the existence of negative regulatory elements in the rat TH promoter has been obtained in transgenic mice (Banerjee et al., 1992; Suri et al., 1993). This model is attractive in light of the species distribution of enzymes in the catecholamine biosynthetic pathway. The TH gene, but not the later ones of the vertebrate pathway, is found in diverse animals including mammals, flies, and nematodes. The DBH gene promoter may therefore have arisen from the broadly expressed TH promoter by the addition of modifiers that restrict gene expression to particular subsets of catecholaminergic neurons.

The regulation of transgenes expressed under control of the DBH promoter can be contrasted with that of other neuronspecific genes in which a different type of negative regulatory element is involved in determining tissuc specificity. In the rat SCG-10 (Wuenschell et al., 1990; Mori et al., 1992) and type II sodium channel (Maue et al., 1990; Kraner et al., 1992) genes, neuron-specific expression is achieved through the combination of positive regulatory elements in the proximal promoter region that direct expression to neuronal and non-neuronal tissues, and a more distal negative regulatory element that restricts expression to neurons. It has been noted previously that the SCG-10 and type II sodium channel genes are members of multigene families, some of whose members are expressed outside the nervous system (Mori et al., 1992). These two genes may therefore share positive regulatory elements with their respective family members so that their unique, neuron-specific expression must be effected by repression in non-neuronal cells. Since the DBH gene does not appear to be a member of such a multigene family, it might be expected that its neuron-specific expression would be mediated by a different type of mechanism. In the DBH gene, tissue-specific expression appears to be mediated by positive distal regulatory elements, while the negative elements serve to refine the cell-specific expression pattern, limiting it to the proper subset of neurons. This is similar to the mechanism involved in the control of most non-neuronal genes, in which tissue specificity is mediated primarily through the action of positive transcription factors at tissue-specific enhancers (Maniatis et al., 1987). In cases where negative elements are present, they usually serve to fine-tune the cell-specific expression (Ishida et al., 1990; Savagner et al., 1990; Shen et al., 1991; Kruse et al., 1993). Our results therefore indicate that common general mechanisms exist for the control of neuronal and non-neuronal gene expression. Further studies will reveal whether any common DNA regulatory elements are involved in the transcriptional control of the DBH gene, other genes in the catecholamine biosynthetic pathway, or other neuron-specific genes.

\section{References}

Baetge EE, Behringer RR, Messing A, Brinster RL, Palmiter RD (1988) Transgenic mice express the human phenylethanolamine $N$-methyltransferase gene in adrenal medulla and retina. Proc Natl Acad Sci USA 85:3648-3652.

Baetge G, Pintar JE, Gershon MD (1990) Transiently catecholaminergic (TC) cells in the bowel of the fetal rat: precursors of noncatecholaminergic enteric neurons. Dev Biol 141:353-380.

Banerjee SA, Hoppe P, Brilliant M, Chikaraishi DM (1992) 5' flanking sequences of the rat tyrosine hydroxylase gene target accurate tissuespecific, developmental, and transsynaptic expression in transgenic mice. J Neurosci 12:4460-4467.

Brinster RL, Chen HY, Trumbauer ME, Yagle MK, Palmiter RD (1985) Factors affecting the efficiency of introducing foreign DNA into mice by microinjecting eggs. Proc Natl Acad Sci USA 82:4438-4442.

Fuxe K, Goldstein M, Hökfelt T, Joh TH (1971) Cellular localization of dopamine $\beta$-hydroxylase and phenylethanolamine $N$-methyltransferase as revealed by immunohistochemistry. Prog Brain Res 34:127138.

Graves RA, Tontonoz P, Ross SR, Spiegelman BM (1991) Identification of a potent adipocyte-specific enhancer: involvement of an NF-1-like factor. Genes Dev 5:428-437.

Grzanna R, Coyle JT (1978) Dopamine $\beta$-hydroxylase in rat submandibular ganglion cells which lack norepinephrine. Brain Res 151: 206-214.

Halász N, Ljungdahl Å, Hökfelt T, Johansson O, Goldstein M, Park D, Biberfeld P (1977) Transmitter histochemistry of the rat olfactory bulb. I. Immunohistochemical localization of monoamine synthesizing enzymes. Support for intrabulbar, periglomerular dopamine neurons. Brain Res 126:455-474.

Ishida I, Verbeek S, Bonneville $M$, Itohara S, Berns A, Tonegawa S (1990) T-cell receptor $\gamma \delta$ and $\gamma$ transgenic mice suggest a role of a $\gamma$ gene silencer in the generation of $\alpha \beta$ T cells. Proc Natl Acad Sci USA 87:3067-3071.

Kapur KP, Hoyle GW, Mercer EH, Brinster RL, Palmiter RD (1991) Some neuronal cell populations express human dopamine $\beta$-hydroxylasc-lac $Z$ transgenes transiently during embryonic development. Neuron 7:717-727.

Kobayashi K, Sasaoka T, Morita S, Nagatsu I, Iguchi A, Kurosawa Y, Fujita K, Nomura T, Kimura M, Katsuki M, Nagatsu T (1992) Genetic alteration of catecholamine specificity in transgenic mice. Proc Natl Acad Sci USA 89:1631-1635.

Kraner SD, Chong JA, Tsay H-J, Mandel G (1992) Silencing the type II sodium channel gene: a model for neural-specific gene regulation. Neuron 9:37-44.

Kruse F, Rose SD, Swift GH, Hammer RE, MacDonald RJ (1993) An endocrine-specific element is an integral component of an exocrine-specific pancreatic enhancer. Genes Dev 7:774-786.

Lamouroux A, Houhou L, Biguet NF, Serck-Hanssen G, Guibert B, Icard-Liepkalns C, Mallet J (1993) Analysis of the human dopamine $\beta$-hydroxylase promoter: transcriptional induction by cyclic AMP. J Neurochem 60:364-367.

Landis SC, Jackson PC, Fredieu JR, Thibault J (1987) Catecholaminergic properties of cholinergic neurons and synapses in adult rat ciliary ganglion. J Neurosci 7:3574-3587. 
Maniatis T, Goodbourn S, Fischer JA (1987) Regulation of inducible and tissue-specific gene expression. Science 236:1237-1245.

Maue RA, Kraner SD, Goodman RH, Mandel G (1990) Neuronspecific expression of the rat brain type II sodium channel gene is directed by upstream regulatory elements. Neuron 4:223-231.

Mercer EH, Hoyle GW, Kapur RP, Brinster RL, Palmiter RD (1991) The dopamine $\beta$-hydroxylase gene promoter directs expression of $E$. coli lac $Z$ to sympathetic and other neurons in adult transgenic mice. Neuron 7:703-716.

Mori N, Schoenherr C, Vandenbergh DJ, Anderson DJ (1992) A common silencer element in the SCG10 and type II $\mathrm{Na}^{+}$channel genes binds a factor present in nonneuronal cells but not in neuronal cells. Neuron 9:45-54.

Morita S, Kobayashi K, Mizuguchi T, Yamada K, Nagatsu I, Titani K, Fujita K, Hidaka H, Nagatsu T (1993) The 5'-flanking region of the human dopamine $\beta$-hydroxylase gene promotes neuron subtype-specific gene expression in the central nervous system of transgenic mice. Mol Brain Res 17:239-244.

Pinkert CA, Ornitz DM, Brinster RL, Palmiter RD (1987) An albumin enhancer located $10 \mathrm{~kb}$ upstream functions along with its promoter to direct efficient, liver-specific expression in transgenic mice. Genes Dev 1:268-276.
Savagner P, Miyashita T, Yamada Y (1990) Two silencers regulate the tissue-specific expression of the collagen II gene. J Biol Chem 265:6669-6674.

Shaskus J, Greco D, Asnani LP, Lewis EJ (1992) A bifunctional genetic regulatory element of the rat dopamine $\beta$-hydroxylase gene influences cell type specificity and second messenger-mediated transcription. J Biol Chem 267:18821-18830.

Shen R, Goswami SK, Mascareno E, Kumar A, Siddiqui MAQ (1991) Tissue-specific transcription of the cardiac myosin light-chain 2 gene is regulated by an upstream repressor element. Mol Cell Biol 11:16761685.

Suri C, Fung BP, Tischler AS, Chikaraishi DM (1993) Catecholamincrgic ccll lincs from the brain and adrenal glands of tyrosine hydroxylase-SV40 T antigen transgenic mice. J Neurosci 13:1280-1291.

Swanson LW, Hartman BK (1975) The central adrenergic system. An immunofluorescence study of the location of cell bodies and their efferent connections in the rat utilizing dopamine $\beta$-hydroxylase as a marker. J Comp Neurol 163:467-506.

Wuenschell CW, Mori N, Anderson DJ (1990) Analysis of SCG10 gene expression in transgenic mice reveals that neural specificity is achieved through selective derepression. Neuron 4:595-602. 